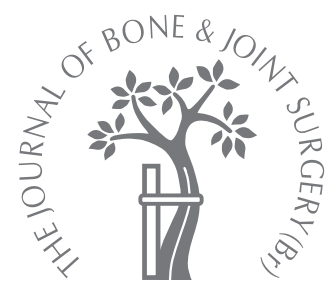

口 REVIEW ARTICLE

\title{
Surgical aspects of the diabetic foot
}

\author{
A. H. N. Robinson, \\ C. Pasapula, \\ J. W. Brodsky
}

From Addenbrooke's Hospital, Cambridge, England

\footnotetext{
A. H. N. Robinson, BSc, FRCS(Orth), Consultant Orthopaedic Surgeon I C. Pasapula, FRCS(Orth), Clinical Fellow, Foot and Ankle Surgery

Department of Orthopaedics Addenbrooke's Hospital, Cambridge University Hospitals NHS Trust, Hills Road, Cambridge CB2 200, UK.

I. J. Brodsky, MD, Clinical Professor of Orthopaedic Surgery and Fellowship Director of Foot and Ankle Surgery

Baylor University Medical Center, 411 North Washington Avenue, Suite 7000, Dallas, Texas 75246, USA

Correspondence should be sent to $\mathrm{Mr}$ A. H. N. Robinson; e-mail: foot.ankle@ntlworld.com

(C)2009 British Editorial Society of Bone and Joint Surgery doi:10.1302/0301-620X.91B1. $21196 \$ 2.00$
}

J Bone Joint Surg $[\mathrm{Br}]$ 2009;91-B:1-7.

\begin{abstract}
A comprehensive review of the literature relating to the pathology and management of the diabetic foot is presented. This should provide a guide for the treatment of ulcers, Charcot neuro-arthropathy and fractures involving the foot and ankle in diabetic patients.
\end{abstract}

The World Health Organisation estimated that 150 million people suffered from diabetes mellitus in the year $2000 .^{1}$ This figure is projected to rise to 366 million by $2030 .^{1}$ In the United Kingdom the cost of treatment of diabetes is thought to account for $9 \%$ of the National Health Service (NHS) hospital budget ${ }^{2,3}$ or $5 \%$ of the overall NHS budget. More than half of this is spent treating the complications. ${ }^{4}$ With high costs and a high prevalence there will be increased focus on the treatment of the diabetic foot in health-care systems which are driven by finance. Presumably it will be less expensive to prevent complications than to manage their consequences. 5

The diabetic foot presents in many different ways to the orthopaedic surgeon. ${ }^{4}$ Nevertheless, broadly there are two groups of patients. First, there are those whose problems result from complications of diabetes which include ulceration, infection and Charcot neuro-arthropathy. Secondly, there are those with a routine problem who coincidentally have diabetes.

Our aim is to provide a basic framework outlining the rationale of diabetic foot care.

\section{Aetiology}

Diabetes leads to two major conditions affecting the foot, neuropathy and vasculopathy. These, in varying combinations, lead to the protean presentation of diabetes in the foot. Neuropathy. Diabetic neuropathy affects the sensory, motor and autonomic nervous system to varying degrees. It is progressive and irreversible and is present in up to $30 \%$ of diabetic patients attending hospital.6,7 The cause is thought to be an ischaemic insult secondary to damage to the vasa nervorum.

The patient may present with the 'negative symptom' of numbness in the feet, ${ }^{8}$ but more commonly presentation is insidious until the onset of complications. The sensory deficit is below the knee, with greater density distally. Occasionally, the distal upper limbs are also involved. Positive symptoms, such as burning pain and paraesthesia, ${ }^{9}$ are less common in diabetic as opposed to other types of neuropathy. It is important to realise that the sensory neuropathy, and not vascular disease, is the primary cause of most foot conditions in diabetic patients. Autonomic neuropathy leads to stiff, dry, and scaly skin, which may crack because of its inflexibility, leading to soft-tissue infection. Motor changes are seen less commonly. Occasionally, patients present with mononeuritis, usually of the peroneal nerve, resulting in foot drop. Motor neuropathy is expressed through its effect on the intrinsic musculature, primarily seen as clawing and hammering of the toes.

Vasculopathy. Diabetic vascular disease involves large and small arteries as well as the microcirculation. Arteriosclerosis in diabetics is more common, more aggressive and more diffuse than that in non-diabetics. The incidence is approximately $45 \%$ after 20 years of duration of the disease. ${ }^{10}$ Unlike non-diabetic arteriosclerosis, involvement below the popliteal trifurcation is common, and the occlusive lesions are diffuse, rather than discrete. Macrovascular disease also causes characteristic circumferential calcification of the tunica media, leading to the radiological 'lead-pipe' appearance of the arteries in the distal limbs. There are also abnormalities of the small vessels and diffusion abnormalities of the capillaries. ${ }^{11}$

\section{Imaging and assessment of the diabetic foot}

Neurological assessment. The importance of a good history and clinical examination of neuropathy cannot be overemphasised. Failure to recognise neuropathy can have disastrous 
consequences in the diabetic patient with an otherwise uncomplicated fracture of the foot and ankle. The use of the $128 \mathrm{~Hz}$ tuning fork ${ }^{12,13}$ and the $10 \mathrm{~g}$ Semmes-Weinstein monofilament is cheap and effective in screening for diabetic peripheral neuropathy. ${ }^{14-17}$

Vascular assessment. The clinical history and palpation of the pulses remain the mainstay of vascular assessment in the diabetic foot. The presence of pulses and the absence of symptoms has a negative predictive value of $96 \%$ in excluding peripheral vascular disease in large vessels. ${ }^{18}$ However, the absence of pulses has a sensitivity of $71 \%$ in predicting peripheral vascular disease, and dictates the need for further vascular assessment. ${ }^{18}$

Indices of ankle/brachial pressure are often unreliable in diabetic patients as a result of the non-compressibility of calcified arteries, leading to false elevation of the index. Apelqvist et $\mathrm{al}^{19}$ showed that toe pressures were more reliable, with healing of $85 \%$ at pressures greater than $45 \mathrm{mmHg}$ and of $36 \%$ between $30 \mathrm{mmHg}$ and $45 \mathrm{mmHg}$. Transcutaneous oxygen tension greater than $30 \mathrm{mmHg}$ has a positive predictive value for healing of $90 \%$, although the equipment for measuring is expensive and the testing complex and timeconsuming. ${ }^{20}$

In selected cases arterial bypass below the knee allows salvage of the foot. Distal grafting has given encouraging results, with grafting of dorsalis pedis having limb-salvage rates of $87 \%$ at five years. ${ }^{21}$

Imaging of the diabetic foot. The main question to be resolved in imaging the diabetic foot is to ascertain whether infection is present or not. In the red, hot, swollen foot differentiating infection from Charcot arthropathy may be necessary.

Standing radiographs in two planes have been shown to have a sensitivity of only $62 \%$ to $75 \%$ in demonstrating osteomyelitis. ${ }^{22,23}$ Diabetic osteolysis distal to the midfoot results in pencilling of the distal metatarsals and vanishing phalanges. ${ }^{24}$ It may not be an infective process, but is in all probability due to hyperaemia. Radiological changes in the absence of a current or a preceding soft-tissue wound rarely represent osteomyelitis, since infection almost always occurs in the diabetic foot by direct extension from adjacent infected soft tissue.

Triple-phase bone scanning has been shown by Jay et $\mathrm{al}^{25}$ to be non-contributory to treatment. Technetium scanning only has a sensitivity of $70 \%$ to $95 \%$ with a specificity of $43 \%$ to $89 \%{ }^{26}$ It should be borne in mind that positive bone scans can occur as a result of Charcot arthropathy. Indium scans alone are also of limited value, with a sensitivity of $79 \%$ and a specificity of $78 \%$ for osteomyelitis. ${ }^{27}$ Dual scanning with indium and technetium is more accurate, but still has limitations with only a sensitivity of $93 \%$ and a specificity of $83 \%^{28,29}$ in localising infection to the bone or soft tissues and is technically demanding.

MRI cannot distinguish between infective oedema and that attributable to Charcot arthropathy. ${ }^{30}$ The main value of MRI is its sensitivity since it has an extremely low false- negative rate which may justify its use in early diagnosis to prevent amputation.

Imaging of the foot is therefore complex and must be taken in the context of the clinical picture. Other than plain radiography, it is infrequently required.

\section{Treatment}

As a result of the differing aetiologies and multi-organ involvement, care of the diabetic foot requires a multidisciplinary approach. The team may include vascular surgeons, endocrinologists, specialists in infectious disease, rehabilitation physicians, orthotists, prosthetists and podiatrists, as well as orthopaedic surgeons. ${ }^{31}$

Ulceration. Ulceration is common in diabetics and is the most common cause of soft-tissue infection leading to hospitalisation and amputation. Boyko et $\mathrm{al}^{14}$ showed that $17 \%$ of diabetic patients developed an ulcer over a period of three years. The primary aetiology of ulceration is excessive pressure on the soft tissues in an insensate foot. This may be exacerbated by poor vascularity and deformity.

It has been shown in an animal model of pressure ulceration that repetitive, blunt trauma of low or moderate degree has a cumulative effect, causing tissue inflammation and subsequent necrosis. ${ }^{32,33}$ The site of the ulceration is indicative of its cause. Plantar ulceration is due to weightbearing whereas ulcers on the dorsum and borders of the foot are usually caused by the pressure of shoes. ${ }^{34}$

In treating an infected ulcer or a deep infection, the patient's general condition, including control of the blood sugar should be optimised. The location, appearance, depth and size of the ulcer should be recorded and the presence or absence of infection noted.

The initial step is to treat the infection. It must be understood that superficial swabs do not accurately represent the deep microbiology. Deep cultures should be obtained. Diabetic infections are characteristically polymicrobial, and empiric antibiotic regimens should reflect this. Definitive antibiotic regimens, based on cultures, generally require more than one antibiotic. Microbiological advice is frequently appropriate.

The treatment of ulceration was first classified and rationalised by Wagner. ${ }^{35}$ Brodsky $^{36}$ observed that Wagner grade- 4 and grade- 5 ulcers were ischaemic and therefore modified the original numerical classification to an alphanumeric pattern (Table I). The numerical grade describes the depth of the ulcer and the alphabet grade the vascularity and these assessments of the ulcer determine treatment (Fig. 1). The grades are described as follows:

Grade 0 . In the foot at risk there is a loss of protective sensibility. The foot requires regular examination and accommodative shoes, including a total contact insole. The insole is contoured to the shape of the foot and made of at least two layers, the upper layer being soft and conforming.

Contracture of the tendo-Achillis occurs in diabetics and leads to an increase in peak forefoot pressures ${ }^{37}$ with consequent ulceration. Peak plantar pressure and recurrence rates 
Table I. Treatment protocol for the diabetic foot as based on the depth-ischaemia classification ${ }^{36}$

\begin{tabular}{cll}
\hline Classification & Definition & Treatment \\
\hline $\begin{array}{cl}\text { Depth } \\
0\end{array}$ & At-risk foot, no ulceration & Patient education, accommodative footwear, regular clinical examination \\
1 & Superficial ulceration, not infected & Off-loading with total contact cast, walking brace or special footwear \\
2 & Deep ulceration exposing tendons or & Surgical debridement, wound care, off-loading, culture-specific antibiotics \\
3 & joints & Debridement or partial amputation, off-loading, culture-specific antibiotics
\end{tabular}

Ischaemia

\begin{tabular}{lll} 
A & Not ischaemic & \\
B & Ischaemia without gangrene & Non-invasive vascular testing and vascular reconstruction with angioplasty/bypass \\
C & Partial (forefoot) gangrene & Vascular reconstruction and partial foot amputation \\
\hline
\end{tabular}

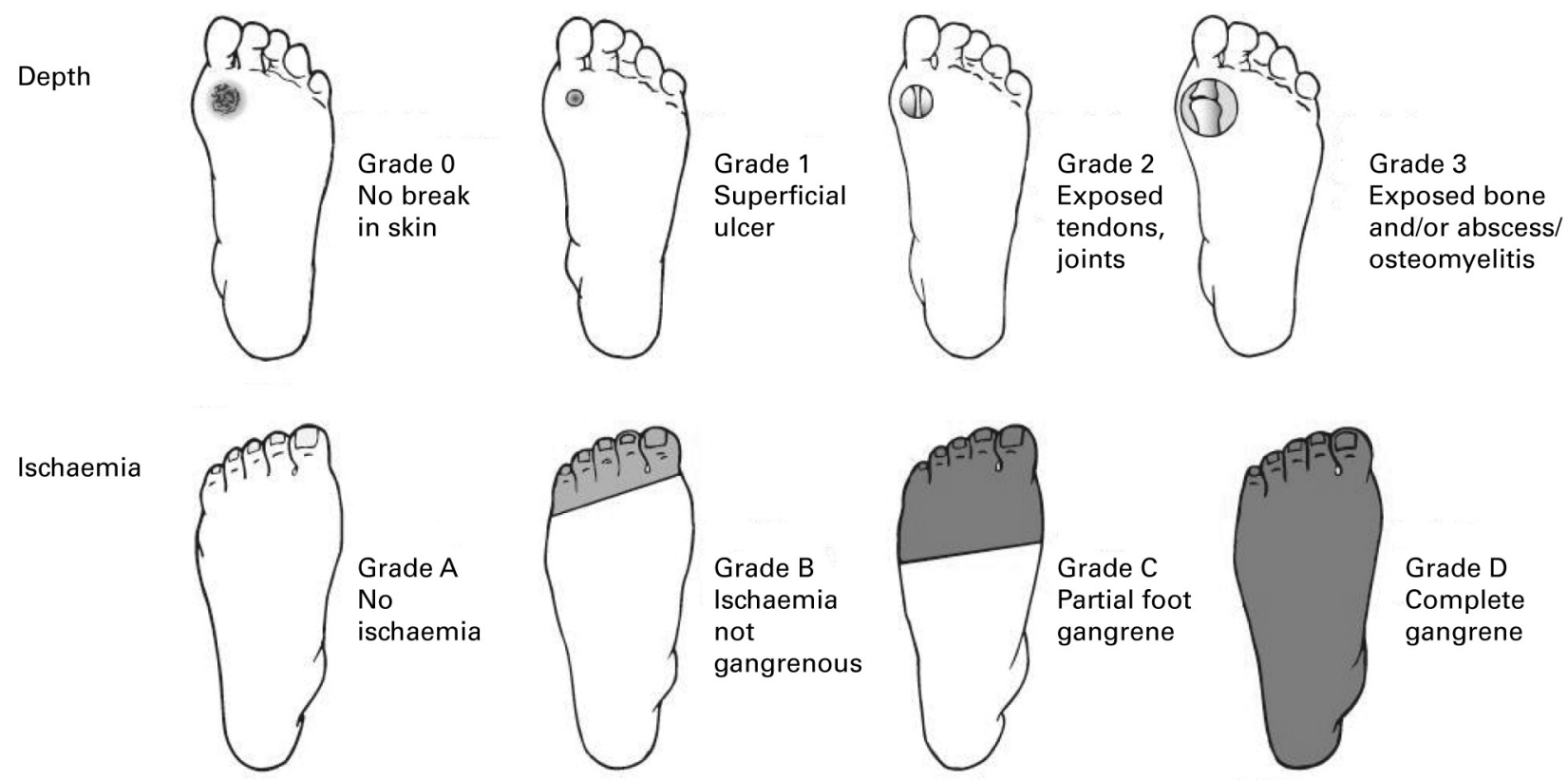

Fig. 1

Diagram of Brodsky's depth-ischemia classification of diabetic foot lesions ${ }^{36}$ (reproduced with permission from Brodsky JW. The diabetic foot. In: Coughlin MJ, Mann RA, Saltzman CL, eds. Surgery of the foot and ankle: Philadelphia: Mosby Elsevier, 2007. p 1297)

of ulcers are $50 \%$ lower at two years in patients who have had lengthening of tendo-Achillis. ${ }^{34}$ A gastrocsoleus slide may be used in patients with recurrent plantar ulceration and ankle dorsiflexion of less than $5^{\circ}$. Nevertheless, lengthening of tendo-Achillis should be undertaken selectively since it has been shown that at eight months the forefoot pressure returns to normal, but plantar flexion remains weak. ${ }^{38}$

Grade 1. These ulcers are superficial with a granulating base and no exposed deep structures. There is no consensus as to the optimal dressing probably because the paramount factor in treatment is reduction of plantar pressure. There are numerous ways of achieving this including nonweight-bearing, the wearing of plastazote shoes and total contact casts. The last remains the treatment of choice for reducing plantar pressure, ${ }^{39-44}$ particularly under the forefoot and midfoot.

In addition to pressure relief, the cast also reduces swelling. Total contact casts can be made using several different techniques, but fabrication is unique in two major ways. ${ }^{45}$ First, the padding is reduced, except over bony prominences, to allow uniform distribution of pressure and to reduce loosening of the cast. Secondly, the toes can be enclosed to redistribute pressure away from the metatarsal heads. Enclosure of the toes also reduces their rubbing against the edge of the cast.

The use of complete non-weight-bearing is both impractical and illusory. ${ }^{46}$ It is impractical in patients who are otherwise ill and debilitated with impaired eyesight. It is illusory 
Table II. Surgical procedures commonly required to assist in the healing of diabetic foot ulcers

\begin{tabular}{ll}
\hline Joint involved* & \\
\hline Hallux IP joint & IP joint condylectomy \\
MTP joint & Dorsiflexion osteotomy of first ray, Keller's arthroplasty \\
First metatarsal head & Dorsiflexion osteotomy of the first ray, medial sesamoid shaving/excision \\
Metatarsal head & TA lengthening, metatarsal head resection, condylectomy, dorsiflexion \\
osteotomy & Condylectomy, head resection, metatarsal head resection \\
Fifth metatarsal head & Resect prominent bone, realignment triple arthrodesis \\
Lateral border & *IP, interphalangeal: MTP metatarsophalangeal: TA, tendo-Achillis
\end{tabular}

*IP, interphalangeal; MTP, metatarsophalangeal; TA, tendo-Achillis

because patients with peripheral neuropathy are unable to perceive whether or not they are truly bearing weight on the limb. In one study, weight-bearing in the first 48 hours was shown to delay healing of the ulcer, ${ }^{40}$ but otherwise it made no difference. Thus, minimal weight-bearing at least is allowed. The cast is changed after the first week, since the reduction in oedema can be very dramatic, leaving the cast loose. After this it is usually changed every two weeks. With appropriate total contact casting, 90\% healing of grade-1 ulcers has been reported at six weeks. ${ }^{40}$ Casting is often continued for one to three weeks after healing to allow the newly epitheliaised wound to mature. If the ulcer fails to heal this may be due to an underlying bony prominence, undiagnosed deep infection or persisting vascular insufficiency. Nevertheless, the most common aetiology is a prominent bone, which may necessitate surgical reconstruction. Table II shows some of the surgical options for correction of deformity leading to recurrent ulcerations.

Grade 2. These ulcers are deeper with an exposed tendon or joint. They usually require formal surgical debridement of exposed and devitalised tissue. Most cannot be treated solely by total contact casting. The presence of copious draining synovial fluid is a poor prognostic indicator for healing and these patients often develop septic arthritis and osteomyelitis with the ulcer being reclassified as grade 3 .

Grade 3. These ulcers show exposed bone, osteomyelitis or an abscess. Intravenous antibiotics cannot be used as the sole method of treatment. Removal of the infected bone or drainage of the abscess should be undertaken.

Differentiating between a grade- 2 and grade- 3 ulcer can be aided by the probe test as described by Grayson et al. ${ }^{47}$ The wound is palpated with a sterile, blunt, solid probe to determine whether there is bone at the base of the ulcer. The reliability of the probe in predicting osteomyelitis is controversial. ${ }^{48}$ Nevertheless, the true value of the probe test is its ability to exclude osteomyelitis with a negative predictive value of $98 \%{ }^{49}$

Unreconstructable vascular disease may necessitate amputation, but in the presence of reconstructable vasculature the outcome in grade-3 lesions is more favourable. It depends upon the location of the deep infection. In the forefoot, resection of infected bone or extensive debridement of soft-tissue infection is compatible with salvage of the foot, and even retention of foot length. This may take the form of amputation of a ray or toe, or of aggressive debridement of the infected area, including bone and soft tissue. With such treatment and preservation of the skin envelope, loose primary closure can often be achieved. This allows quicker healing. Ideally, the skin flaps are maximised and the infected area is excised en bloc. The wound should be lavaged with copious amounts of sterile saline. Microbiological specimens are taken at the end of the debridement to determine the level of infection of the residual wound. Depending on the results of cultures, the length of the post-operative course of antibiotics varies between two and six weeks.

Even if partial amputation is required, with current surgical techniques, salvage of the foot is the rule, rather than the exception. If the osteomyelitis involves the midfoot, Chopart (talonavicular-calcaneocuboid disarticulation) or a Syme amputation are often successful. If the osteomyelitis involves the hindfoot, the key issue is the ability to salvage the heel. Without a heel which has viable and stable softtissue cover, salvage of the foot is precluded. The exceptions are patients with limited infection of the posterior calcaneal tubercle. In these, partial calcanectomy can often salvage the foot. The patient will usually need to wear a shoe with an ankle-foot orthosis. ${ }^{50}$

Charcot neuro-arthropathy. Diabetes mellitus is the most common cause of Charcot neuro-arthropathy in the Western world. ${ }^{51}$ Two principal pathways for the disease have been proposed. The neurotraumatic theory suggests that the loss of neuroprotection causes repetitive microtrauma. The opposing hypothesis, the neurovascular, is that sympathetic neuropathy results in hyperaemia. This leads to increased osteoclastic activity resulting in bone resorption and fragmentation. In all probability both processes are involved. Saltzman's group ${ }^{52}$ has shown that patterns of fracture in Charcot neuro-arthropathy are more common in the ankle and forefoot, whereas dislocation predominates in the midfoot. The patterns of fracture in neuroarthropathy is associated with a low peripheral bone mineral density, whereas in dislocation the peripheral bone mineral density in normal.

In the acute phase the foot is typically swollen and inflamed. It is not dysvascular, although the pulses may be obscured by extensive swelling. Most patients with Charcot arthropathy experience pain, although the pain is not commensurate with the degree of injury. Clinically, it may be dif- 


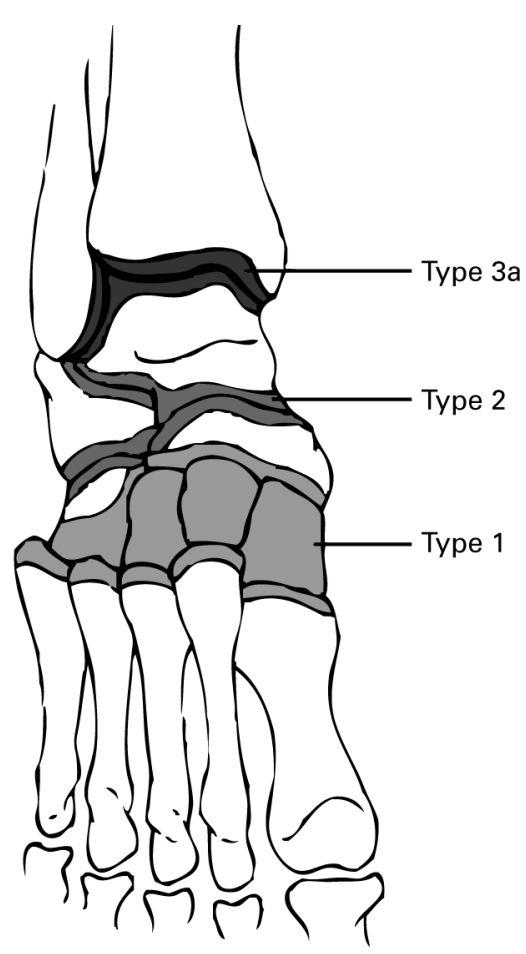

Fig. $2 a$

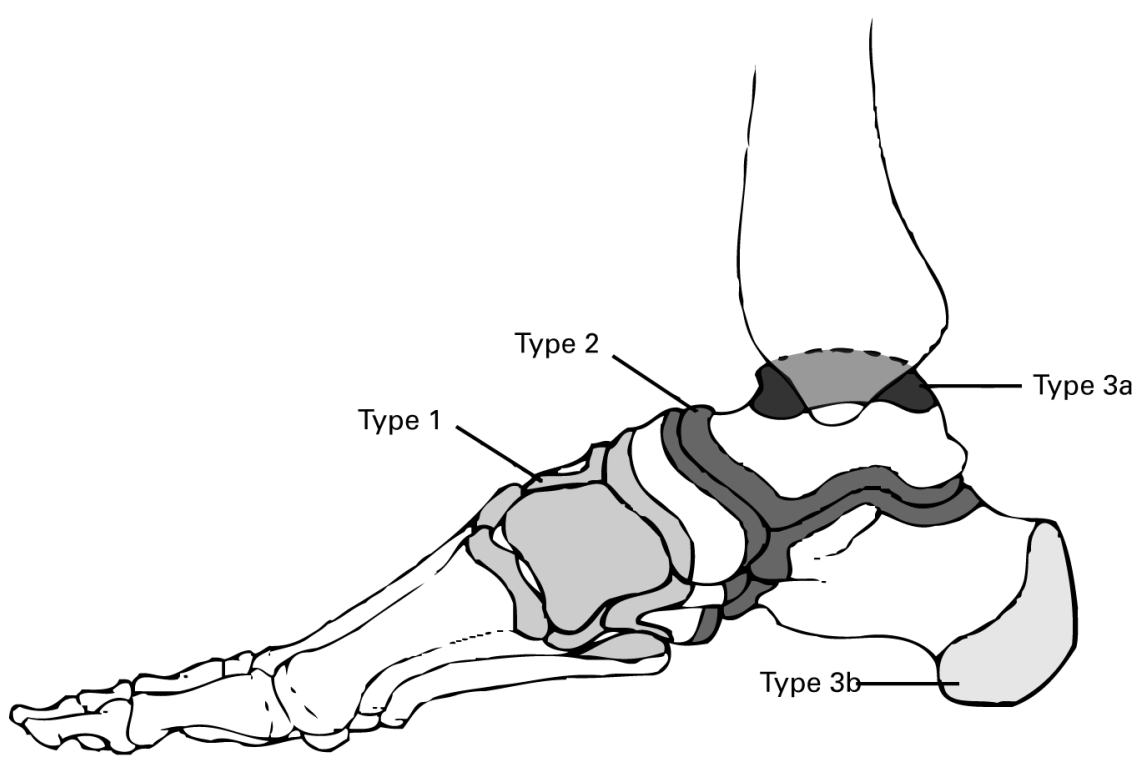

Fig. 2b

a) Anteroposterior and b) lateral diagrams showing the classification of Charcot arthropathy of the foot and ankle (reproduced with permission from Brodsky JW. The diabetic foot. In: Coughlin MJ, Mann RA, Saltzmann CL, eds. Surgery of the foot and ankle: Philadelphia: Mosby Elsevier, 2007; 1341).

ficult to distinguish the inflammation of an acute Charcot foot from that of infection. Technetium ${ }^{99}$ scans are unhelpful. MRI is often non-specific and inconclusive. Pragmatically, the development of deep infection is extremely unlikely in the absence of disruption to the skin, prior ulceration or previous surgery. Deep infection in the diabetic foot almost always occurs by extension from a contiguous soft-tissue focus, and almost never as the result of haematogenous seeding. Thus, if the skin has not been breached, the likely diagnosis is a non-infected Charcot arthropathy.

The natural history of the Charcot foot is one of gradual healing over many months. It can take more than a year. As the acute inflammation and swelling subside new bone forms, leading to consolidation of the foot. The goal of treatment is to maintain a plantigrade foot which will allow weight-bearing in a shoe or brace.

The mainstay of the treatment of Charcot arthropathy is a total contact cast, to maintain position during the healing phase. As the foot heals the patient is weaned into a removable pre-fabricated brace or a bivalved custom-moulded polypropylene ankle-foot orthosis. ${ }^{53}$ When the radiographs show evidence of healing and the temperature of the foot returns to normal the patient is then fitted with an accommodative shoe with a moulded insole.

The incidence of diabetic neuroarthropathy varies among the anatomical regions of the foot and ankle (Fig. 2). Approximately $70 \%$ of cases affect the tarsometatarsal joint (type 1). ${ }^{54}$ Type-1 disease is the least likely to require surgical stabilisation, although the most common type to cause plantar ulceration. Type-2 disease involves the midtarsal and subtalar joints and accounts for approximately $20 \%$ of cases. Type- 3 disease affects approximately $10 \%$ of patients, and occurs mainly in the ankle. Type 2 and type 3 are the most likely to progress to instability and often require long-term bracing or surgical reconstruction.

The major complication of Charcot neuro-arthropathy is deformity leading to secondary ulceration. ${ }^{55}$ Type- 1 injuries lead to a rocker-bottom foot with ulceration under the midfoot. In most cases this can be treated by a simple exostectomy, when an incision is made on the border of the foot and the prominent bone excised. ${ }^{56}$ Occasionally, an arthrodesis with internal fixation is required. Occasionally, severe deformity develops in the coronal plane. This is most commonly seen in type-3a ankles. It is possible to treat these patients in a bivalved ankle-foot orthosis but in many cases surgical stabilisation is required. A combined ankle and subtalar fusion with transcalcaneal nail fixation is often used. ${ }^{57}$ Surgery is undertaken once the acute inflammatory stages have subsided, and bony consolidation has begun.

Type-3b disease is an avulsion of the insertion of tendoAchillis. This is similar to the parrot-beak calcaneal fracture, but in the diabetic it does not require surgical reduction and fixation. A short period of treatment in a cast and then provision of a shoe with a heel raise are adequate. 
Our opinion is that most patients with Charcot neuroarthropathy can be treated non-operatively and stabilised in a total contact cast.

Fractures. In diabetic patients fractures of the foot and ankle merit special consideration. In the presence of diabetic neuropathy there is no absolute distinction between Charcot neuro-arthropathy and traumatic fracture. In this section we discuss the treatment of acute ankle fractures caused by trauma in diabetics.

It should be noted that there is a high rate of complication from ankle fractures in diabetic patients. ${ }^{58,59}$ It is important to be aware of the diagnosis of diabetes and document the presence or absence of neuropathy, vascular disease and other diabetic complications. ${ }^{60}$ Diabetic patients with an acute fracture of the ankle who have a history of previous Charcot neuroarthropathy have a poor prognosis, even if the neuro-arthropathy is in another anatomical site. ${ }^{61}$

Complications include nonunion, loss of fixation, malunion, wound problems and severe deformity from secondary Charcot neuro-arthropathy. Peripheral neuropathy is the most common cause of these complications followed by vascular disease. ${ }^{60}$

In the diabetic patient with an acute ankle fracture the reconstruction of severely compromised arterial circulation takes priority. If vascular reconstruction is not achievable then surgical reconstruction may result in below-knee amputation. Non-operative treatment is mandatory, but prone to failure. Costigan, Thordarson and Debnath ${ }^{62}$ showed that ten of 12 patients with absent foot pulses developed complications.

Stable ankle fractures are typically treated nonoperatively with an increased duration of immobilisation. ${ }^{60}$

Unstable ankle fractures should be treated operatively in diabetics who do not have peripheral vascular disease. There are no randomised controlled trials to support operative intervention, but we believe that in displaced fractures, early stability and alignment should be achieved by fixation. This provides a stable environment for the healing of the soft tissues and the fracture. In the largest series of operatively treated diabetic fractures treated to date there was an overall complication rate of $14 \% .{ }^{63}$ This is high, but lower than that reported in non-operatively treated fractures. Flynn et $\mathrm{al}^{59}$ showed that the rate of infection after surgery was increased in diabetics. Nevertheless, the highest rate was seen in the diabetics treated nonoperatively in plaster (four of six patients).

Effective fixation in diabetics with peripheral osteoporosis can be challenging, especially as bulky implants cannot be used in the presence of poor soft tissues. Use of the antiglide technique with a plate over the posterior fibula can maximise stability when bone quality is poor. Augmentation by transarticular, subcutaneous pins has been advocated. ${ }^{53}$

Adequate post-operative immobilisation is thought to be important to reduce the risk of Charcot neuro-arthropathy. Johnson ${ }^{53}$ has suggested that the immobilisation time should be increased in all patients with neuropathy, and advocates a period of non-weight-bearing of three months followed by weight-bearing in a cast for a further two to three months. This is then followed by the use of a brace for one year. We suggest doubling of the standard immobilisation time.

In summary, patients with diabetic foot problems present a host of problems and challenges, and often an acute orthopaedic problem. Recognition of the particular risks and complications is critical to achieving a satisfactory outcome in this ever-increasing group of patients.

No benefits in any form have been received or will be received from a commercial party related directly or indirectly to the subject of this article.

\section{References}

1. Wild S, Roglic G, Green A, Cicree R, King H. Global prevalence of diabetes: estimates for the year 2000 and projections for 2030. Diabetes Care 2004;27:1047-53.

2. Apelqvist J, Ragnarson-Tennvall G, Larsson J, Persson U. Long-term costs for foot ulcers in diabetic patients in a multidisciplinary setting. Foot Ankle Int 1995; 16:388-94.

3. No authors listed. Diabetes key facts: http://www.diabetes.nhs.uk/downloads/ YHPHO (date last accessed October 2007).

4. Newrick P. International consensus on the diabetic foot. BMJ 2000;321:642

5. Ortegon MM, Redekop WK, Niessen LW. Cost-effectiveness of prevention and treatment of the diabetic foot: a Markov analysis. Diabetes Care 2004;27:901-7.

6. Walters DP, Gatling W, Mullee MA, Hill RD. The prevalence of diabetic distal sensory neuropathy in an English community. Diabet Med 1992;9:349-53.

7. Tesfaye S, Stevens LK, Stephenson JM, et al. Prevalenece of diabetic peripheral neuropathy and its relation to glycaemic control and potential risk factors: the EURODIAB IDDM complication study. Diabetologia 1996;39:1377-84.

8. Rathur RM, Boulton HAM. Recent advances in the diagnosis and management of diabetic neuropathy. J Bone Joint Surg [Br]2005;87-B:1605-10.

9. Oyibo SO, Prasad YD, Jackson NJ, Jude EB, Boulton AJM. The relationship between blood glucose excursions and painful diabetic peripheral neuropathy: a pilot study. Diabetic Medicine 2002;10:870-3

10. Melton LJ, Macken KM, Palumbo PJ, Elveback LR. Instance and prevalence of clinical peripheral vascular disease in a population based cohort of diabetic patients. Diabetes Care 1980;3:650-4.

11. Boulton A. A pathway to ulceration aetiopathogenesis. The foot in diabetes. Second edition. 1994:37-48.

12. Meijer JG, Smit AJ, Lefrandt JD, et al. Back to basics in diagnosing diabetic polyneuropathy with the tuning fork. Diabetic Care 2005;28:2201-5.

13. Gin H, Rigalleau V, Baillet L, Rabemanantsoa C. Comparison between monofilament, tuning fork and vibration perception tests for screening patients at risk of foot complication. Diabetes Metab 2002;28:457-61.

14. Boyko EJ, Ahroni JH, Cohen V, Nelson KM, Heagerty PJ. Prediction of diabetic foot ulcer occurrence using commonly available clinical information. Diabetic Care 2006;29:1202-7.

15. Klenerman L. Screening for patients at risk of diabetic foot ulceration in a genera diabetic outpatient clinic. Diabet Med 1996;13:561-3.

16. Pham H, Armstrong DG, Harvey C, et al. Screening techniques to identify people at high risk for diabetic foot ulceration: a prospective multicentre trial. Diabetes Care 2000;23:606-11.

17. Rith-Najarian SJ, Stolusky T, Gohdes DM. Identifying diabetic patients at high risk for lower-extremity amputation in a primary health care setting: a prospective evaluation of single screening criteria. Diabetes Care 1992;15:1386-9.

18. Criqui MH, Fronek A, Klauber MR, Barrett-Connor E, Gabriel S. The sensitivity, specificity, and predictive value of traditional clinical evaluation of peripheral arterial disease: results from noninvasive testing in a defined population. Circulation 1985:71:516-22.

19. Apelquist J, Castenfors J, Larsson J, Stenstrom A, Agardh CD. Prognostic value of systolic ankle and toe blood pressure levels in outcome of diabetic foot ulcer. Diabetes Care 1989;6:373-8.

20. Kalani M, Brismar K, Fagrell B, Ostergren J, Jorneskog G. Transcutaneous oxy gen tension and toe blood pressure as predictors for outcome of diabetic foot ulcers. Diabetes Care 1999;22:147-51.

21. Verhelst R, Brunea $\mathbf{M}$, Nicolas $\mathbf{A}-\mathbf{L}$, et al. Popliteal-to-distal bypass grafts for limb salvage. Ann Vasc Surg 1997;11:505-9.

22. Yuh WT, Corson JD, Baraniewski HM, et al. Osteomyelitis of the foot in diabetic patients: evaluation with plain film, 99mTc-MDP bone scintigraphy, and MR imaging AJR Am J Roentgenol 1989;152:795-800. 
23. Park HM, Wheat LJ, Siddiqui AR, et al. Scintigraphic evaluation of diabetic osteomyelitis: concise communication. J Nucl Med 1982;23:569-73.

24. Kraft E, Spyropoulos E, Finby N. Neurogenic disorders of the foot in diabetes mellitus Am J Roentgenol Radium Ther Nucl Med 1975;124:17-24.

25. Jay PR, Michelson JD, Mizel MS, Magid D, Le T. Efficacy of three-phase bone scans in evaluation diabetic foot ulcers. Foot Ankle Int 1999;20:347-55.

26. Gold RH, Tong DJF, Crim JR, Seeger LL. Imaging the diabetic foot. Skeletal Radiol 1995;24:563-71.

27. Larcos G, Brown ML, Sutton RT. Diagnosis of osteomyelitis of the foot in diabetic patients: value of 111 in-leukocyte scintigraphy. AJR Am J Roentgenol 1991;157:527-31.

28. Crerand $\mathbf{S}$, Dolan $\mathbf{M}$, Laing $\mathbf{P}$, et al. Diagnosis of osteomyelitis in neuropathic foot ulcers. J Bone Joint Surg [Br] 1996;78-B:51-5.

29. Schauwecker DS, Park HM, Burt RW, Mock BH, Wellman HN. Combined bone scintigraphy and indium-111 leukocyte scans in neuropathic foot disease. J Nucl Med 1988;29:1651-5

30. Moore TE, Yuh WT, Kathol MH, el-Khoury GY, Corson JD. Abnormalities of the foo in patients with diabetes mellitus: findings on MR imaging. AJR Am J Roentgenol 1991;157:813-16

31. Dargis V, Pantelejeva 0, Jonushaite A, Vileikyte L, Boulton AJ. Benefits of a multidisciplinary approach in the management of recurrent diabetic foot ulceration in Lithuania: a prospective study. Diabetes Care 1999;22:1428-31.

32. Brand PW. Repetitive stress in the development of diabetic foot ulcers. In: Levin ME, Davidson JK, eds. The diabetic foot. Fourth edition. Mosby, St. Louis, Missouri, 1988:8390

33. Manley MT, Darby T. Repetitive mechanical stress and denervation in plantar ulcer pathogenesis in rats. Arch Phys Med Rehabil 1980;61:171-7.

34. Mueller MJ, Sinacore DR, Hastings MK, Strube MJ, Johnson JE. Effect of Achilles tendon lengthening on neuropathic plantar ulcers: a randomized clinical trial. J Bone Joint Surg $[A m] 2003 ; 85-A: 1436-45$

35. Wagner F. Classification and treatment programme for diabetic, neuropathic and dysvascular foot problems. Inst Course Lect 1977;122:62.

36. Brodsky JW. Outpatient diagnosis and management of the diabetic foot. Inst Course Lect 1979;28:143-65.

37. Armstrong DG, Stacpoole-Shea S, Nguyen H, Harkless LB. Lengthening of the Achilles tendon in diabetic patients who are at high risk for ulceration of the foot. J Bone Joint Surg [Am] 1999;81-A:535-8.

38. Maluf S, Mueller MJ, Strube MJ, Engsberg JR, Johnson JE. Tendon Achilles lengthening for the treatment of neuropathic ulcers causes a temporary reduction forefoot pressure associated with changes in plantar flexon power rather than ankle motion during gait. J Biomech 2004;37:897-906.

39. Mueller MJ, Diamond JE, Sinacore DR, et al. Total contact casting in treatment of diabetic plantar ulcers: controlled clinical trial. Diabetes Care 1989;12:384-8.

40. Myerson M, Papa J, Eaton K, Wilson K. The total-contact cast for management of neuropathic plantar ulceration of the foot. J Bone Joint Surg [Am]1992;74-A:261-9.

41. Armstrong DG, Lavery LA, Wu S, Boulton AJ. Evaluation of removable and irremovable cast walkers in the healing of diabetic foot wounds: a randomized controlled trial. Diabetes Care 2005;28:551-4.

42. Nabuurs-Franssen MH, Sleegers R, Huijberts MSP, et al. Total contact casting of the diabetic foot in daily practice: a prospective follow-up study. Diabetes Care 2005:28:243-7.
43. Lehto S, Ronnemaa T, Pyorala K, Laakso M. Risk factors predicting lower extremity amputations in patients with NIDDM. Diabetes Care 1996;19:607-12.

44. Armstrong DG, Nguyen HC, Lavery LA. Off-loading the diabetic foot wound: a randomized clinical trial. Diabetes Care 2001;24:1019-22.

45. Trepman E, Pinzur MS, Shields NN. Application of the total contact case. Foot Ankle Int 2005;26:108-12.

46. Saltzman CL, Zimmerman MB, Holdsworth RL, et al. Effect of initial weight-bearing in a total contact cast on healing of diabetic foot ulcers. J Bone Joint Surg [Am]2004;86A:2714-19.

47. Grayson ML, Gibbons GW, Balogh K, Levin E, Karchmer AW. Probing to bone in infected pedal ulcers: a clinical sign of underlying osteomyelitis in diabetic patients. JAMA 1995;273:721-3.

48. Lavery LA, Armstrong DG, Peters EJ, Lipsky BA. Probe-to-bone test for diagnosing diabetic foot osteomyelitis: reliable or relic? Diabetes Care 2007;30:270-4.

49. Shone A, Burnside J, Chipchase S, Game F, Jeffcoate W. Probing the validity of the probe-to-bone test in the diagnosis of osteomyelitis of the foot in diabetes. Diabetes Care 2006;29:945

50. Crandall RC, Wagner FW Jr. Partial and total calcanectomy: a review of thirty-one consecutive cases over a ten-year period. J Bone Joint Surg [Am]1981;63-A:152-5.

51. Brodsky JW. The diabetic foot. In: Coughlin MJ, Mann RA, Saltzman CL eds. Surgery of the foot and ankle. Philadelphia: Mosby Elsevier, 2007:1333.

52. Herbst SA, Jones KB, Saltzman CL. Pattern of diabetic neuropathic arthroplasty assocated with the peripheral bone mineral density. J Bone Joint Surg [BrN2004;86-B:378-83.

53. Johnson JE. Operative treatment of neuropathic arthropathy of the foot and ankle. $J$ Bone Joint Surg [Am] 1998;80-A:1700-9.

54. Brodsky JW. Patterns of breakdown in the Charcot tarsus of diabetics and relation to treatment. Foot and Ankle 1986;5:353.

55. Armstrong DG, Lavery LA. Elevated peak plantar pressures in patients who have Charcot arthropathy. J Bone Joint Surg [Am]1998;80-A:365-9.

56. Brodsky JW, Rouse AM. Exostectomy for symptomatic bony prominences in diabetic charcot feet. Clin Orthop 1993;296:21-6.

57. Schwarz RJ, Macdonald MR, van der Pas M. Result of arthrodesis in neuropathic feet. J Bone Joint Surg [Br] 2006;88-B:747-50.

58. McCormack RG, Leith JM. Ankle fractures in diabetics: complications of surgical management. J Bone Joint Surg [Br] 1998;80-B:689-92.

59. Flynn JM, Rodriguez-del Rio F, Piza PA. Closed ankle fractures in the diabetic patient. Foot Ankle Int 2000:21:311-19.

60. Bibbo C, Lin SS, Beam HA, Behrens FF. Complications of ankle fractures in diabetic patients. Orthop Clin North Am 2001;32:113-33.

61. Jones JB, Maiers-Yelden KA, Marsh JL, et al. Ankle fractures in patients with diabetes mellitus. J Bone Joint Surg [Br] 2005;87-B:489-95

62. Costigan W, Thordarson DB, Debnath UK. Operative management of ankle fractures in patients with diabetes mellitus. Foot Ankle Int 2007;28:32-7.

63. Ayoub MA. Ankle fractures in diabetic neuropathic arthroplasty: can tibiotalar arthrodesis salvage the limb? J Bone Joint Surg [Br]2008;90-B:906-14. 